\title{
A New Allogromiid Foraminifer from coastal Georgia, USA: The Case for an Unusual Form of Chloroplast Sequestration
}

\author{
S.T. Goldstein*, A. Habura**, E.A. Richardson***, and S.S. Bowser** \\ *University of Georgia, Department of Geology, Athens, GA 30602 \\ ** Wadsworth Center, NY State Dept Health, Albany, NY 12201-0509 \\ ***University of Georgia, Department of Plant Biology, Athens, GA 30602
}

The allogromiid foraminiferan protists comprise a series of basal clades that include naked, organicwalled, and monothalamous agglutinated taxa [1-2]. Representatives are known from marginal marine settings to the deep sea, and in selected freshwater settings and terrestrial soils [3].

Molecular studies [4-5] have shown that the biodiversity of allogromiids is considerably higher than that recognized using traditional collecting methods, and as a result we know little about the adaptations and modes of life of this group.

The many mudflats associated with the expansive salt marshes of coastal Georgia host an interesting array of mostly undescribed allogromiids in addition to other foraminiferal taxa. Among the new allogromiids is a small $(<200 \mu \mathrm{m})$ translucent monothlamous species (Fig. 1). Molecular analyses show that this foraminifer belongs to "allogromiid clade E", a grouping that includes the sand-ingesting Psammophaga simplora. The test (shell) of this new allogromiid (Fig. 2) shares many of the constructional features found in P. simplora: both have a prominent agglutinated layer that consists of clays and bioadhesive, underlain by an inner organic lining.

By light microscopy, non-reproductive individuals of this new allogromiid appear golden-brown, reflecting the ingestion of numerous diatoms (Fig. 3-4). In general, diatoms are a common food resource for many shallow-water Foraminifera, and it is not uncommon to find their partially or fully digested remains within foraminiferal food vacuoles [6]. What is unusual about the diatoms ingested by this allogromiid is that the chloroplasts remain structurally intact and have an undigested, pristine appearance (Fig. 5), much like those found in the $\sim 15$ calcareous, benthic species of Foraminifera known to sequester diatom chloroplasts [7]. These calcareous benthic taxa possess tests equipped with various denticles and protrusions thought to aid the foraminifer in breaking open diatom frustules and isolating the choloroplasts [7-8]. Because this allogromiid possesses only a soft, flexible test, we suggest that it is unable to separate chloroplasts from diatoms, and rather ingests entire diatoms to "sequester" their chloroplasts.

\section{References}

[1] J. Pawlowski et al., J. Foraminiferal Res. 2 (2002) 334.

[2] J. Pawlowski et al., Proc. Nat. Acad. Sci. 100 (2003) 11494.

[3] T. Cedhagen et al., J. Foraminiferal Res. 32 (2002) 331, and refs. therein.

[4] J. Pawlowski et al., Polar Biol. 25 (2002) 96.

[5] A. Habura et al., J. Eukaryotic Microbiol. 51 (2004) 173.

[6] S.T. Goldstein and B.H. Corliss Deep-Sea Res. 41 (1994) 229.

[7] J.M. Bernhard and S.S. Bowser Earth-Sci. Rev. 46 (1999) 149.

[8] H.A. Austin et al., Mar. Micropal. 57 (2005) 68.

Supported by NSF grant DEB0445181. 


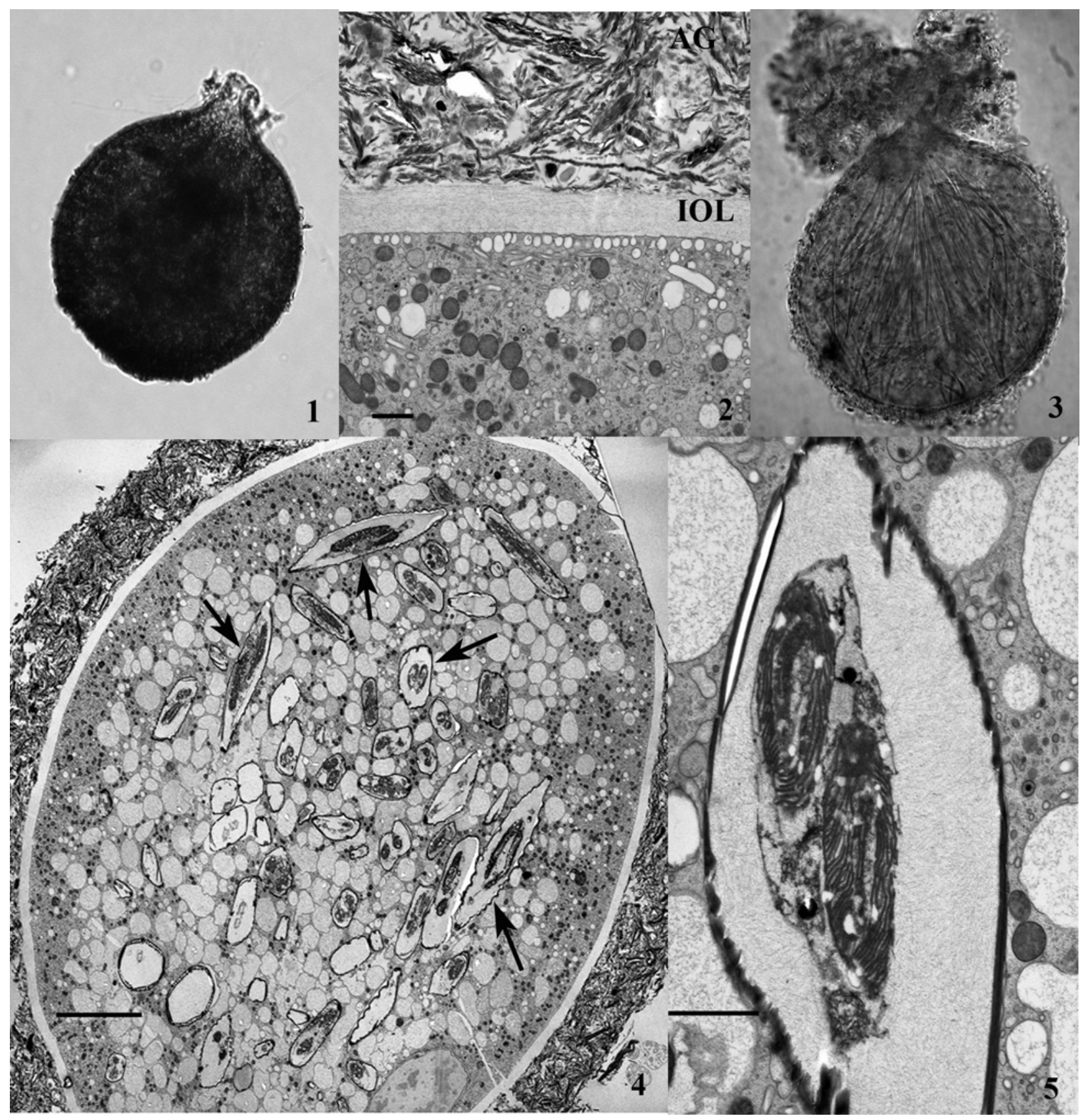

Fig. 1. (Reflected) light micrograph of new allogromiid foraminifer ( 200 $\mu \mathrm{m})$.

Fig. 2. Fine structure (TEM) of the test (shell) with prominent agglutinated layer (AG), and inner organic lining (IOL) which is in direct contact with cytoplasm. Bar $=1 \mu \mathrm{m}$.

Fig. 3. (Transmitted) light micrograph of an individual $(\sim 200 \mu \mathrm{m})$ completely stuffed with diatoms. Fig. 4. TEM (Low-mag) of individual filled with diatoms with intact chloroplasts. Bar $=10 \mu \mathrm{m}$.

Fig. 5. TEM of ingested diatom with intact chloroplasts. Bar $=1 \mu \mathrm{m}$. 